\title{
Profit Efficiency of Rice Farms in Wet-Season Lowlands in Champhone District, Savannakhet Province, Lao PDR
}

\author{
Sengphachan Khounthikoumane ${ }^{1}$, Jae Bong Chang ${ }^{2}$ (I) and Yoonsuk Lee ${ }^{1, *}$ \\ 1 Department of Agricultural \& Resource Economics, Kangwon National University, Chuncheon 24341, Korea; \\ senphachan_k@yahoo.com \\ 2 Department of Food Marketing and Safety, Konkuk University, Seoul 05029, Korea; jbchang@konkuk.ac.kr \\ * Correspondence: yoonsuklee@kangwon.ac.kr
}

Citation: Khounthikoumane, S.; Chang, J.B.; Lee, Y. Profit Efficiency of Rice Farms in Wet-Season Lowlands in Champhone District, Savannakhet Province, Lao PDR. Agriculture 2021, 11, 657. https://doi.org/10.3390/ agriculture11070657

Academic Editors: Gordon Rausser and WIIliam Foster

Received: 9 June 2021

Accepted: 8 July 2021

Published: 12 July 2021

Publisher's Note: MDPI stays neutral with regard to jurisdictional claims in published maps and institutional affiliations.

Copyright: (c) 2021 by the authors. Licensee MDPI, Basel, Switzerland. This article is an open access article distributed under the terms and conditions of the Creative Commons Attribution (CC BY) license (https:// creativecommons.org/licenses/by/ $4.0 /)$.

\begin{abstract}
This study analyzed factors affecting profit efficiency of rice farms in wet-season lowlands in the Champhone District of Savannakhet Province in the Lao People's Democratic Republic based on a farmer's decision to maximize profits. The profit efficiency approach has an advantage in that it provides insights into both inputs and outputs. To analyze profit efficiency, the stochastic production frontier model with assumptions about the time period and types of inputs was applied in the study. The study found similar results to previous studies related to efficiency measurements using a stochastic frontier analysis. Rice production and selling prices have positive signs with respect to the rate of return; however, costs of labor, seed, irrigation, fertilizers, and maintenance have negative signs with respect to the rate of revenue. However, the results from the inefficiency model showed the different role of education. The previous studies found that education level did not play an important role in improving rice productivity in Laos, however, the present study found that education level played a significant role in increasing profits.
\end{abstract}

Keywords: stochastic frontier model; profits efficiency; wet-season lowland rice

\section{Introduction}

Analyzing farm efficiency provides information to decision makers in order to improve the agricultural sector in many developing countries. Farm efficiency can be measured in terms of production, cost, and profit [1]. However, most studies on farm efficiency have focused on agricultural production based on the relationships between inputs and outputs [2]. When technical efficiency is measured with a production frontier model, it is assumed that the farmer maximizes output under the given inputs [3]. The ultimate goal of maximizing the output is directly related to an increase in profits. In order to gain more profits in a competitive market, farmers can choose to produce more, reduce costs, or both Based on the behaviors of cost minimization, farmers consider the combination of least-cost inputs in order to achieve efficiency, while maintaining the same level of output. As a frontier approach for cost minimization measures inefficiency related to inputs, it provides fragmentary insights associated with inputs. However, in the efficiency measurement for profit maximization, inputs and outputs can be considered as choice variables [4], i.e., the inefficiency of a farm is determined on the basis of various aspects. In order to understand all possibilities of yield inefficiency in wet-season lowland rice farms in the Lao People's Democratic Republic (henceforth Laos), a profit efficiency model was utilized in this study.

Most farm households in Laos engage in rice farming, and rice is a major source of income. According to the Ministry of Agriculture and Forestry, rice cultivation area in Laos was 948,029 ha in 2018, which accounts for 75 percent of the total crop area; the remaining 25 percent was dedicated to the cultivation of maize, cassava, starchy roots, vegetables, etc. [5]. Rice production in Laos is classified into wet and dry seasons according to climatic conditions, and more specifically, into upland, lowland rainfed, and lowland irrigated [6]. In 2018, lowlands and uplands comprised 784,368 ha and 87,091 ha, respectively, during 
the wet season; irrigated land comprised 87,091 ha in the dry season. In 2018, total rice production in the wet-season lowlands was 3,022,655 tons, and in the dry season was 402,100 tons. When comparing the productivity in the wet and dry-season lowlands, productivity during the wet season was $4.37 \mathrm{ton} / \mathrm{ha}$, while this was 5.26 tons/ha in the dry season [5]. Although the cultivation area during the wet season is approximately nine times bigger than the area in the dry season, productivity is lower. Rice production in Laos has significantly increased and thus Laos has reached rice self-sufficiency at the national level. However, there are several areas still suffering from rice deficit [7]. In order to overcome regional differences with regards to rice deficit, the Laos government has improved productivity. Although rice productivity has improved, it is not certain that this directly leads to increased profit. Most studies on rice production in Laos have focused on inefficiency factors affecting productivity [8-10].

This study focused on whether rice farms experience increased profits after improving productivity. We directly estimated factors affecting the profit efficiency of rice farms. In order to estimate profit efficiency, a stochastic frontier model is used. The primary data are collected from 230 farm households that cultivate rice in the wet-season lowlands in the Champhone District of Savannakhet Province in Laos.

\section{Materials and Methods}

\subsection{Study Area}

Laos is divided into 18 provinces and 148 districts. Of the 148 districts, 23 are poor, and have joined in the priority development plan supported by the Ministry of Agriculture and Forestry's Department of Rural Development and Association [11]. The Champhone District in Savannakhet Province was selected for this study because this province is a well-known place for agriculture, and around 90 percent of villagers in the Champhone District are engaged in rice farming in wet-season lowlands. Figure 1 shows a map of the Champhone District in the Savannakhet Province. The total area of the Champhone District is $1065 \mathrm{~km}^{2}$, and the total population 109,174, according to the Population and Housing Census of Lao Statistics Bureau (2015).

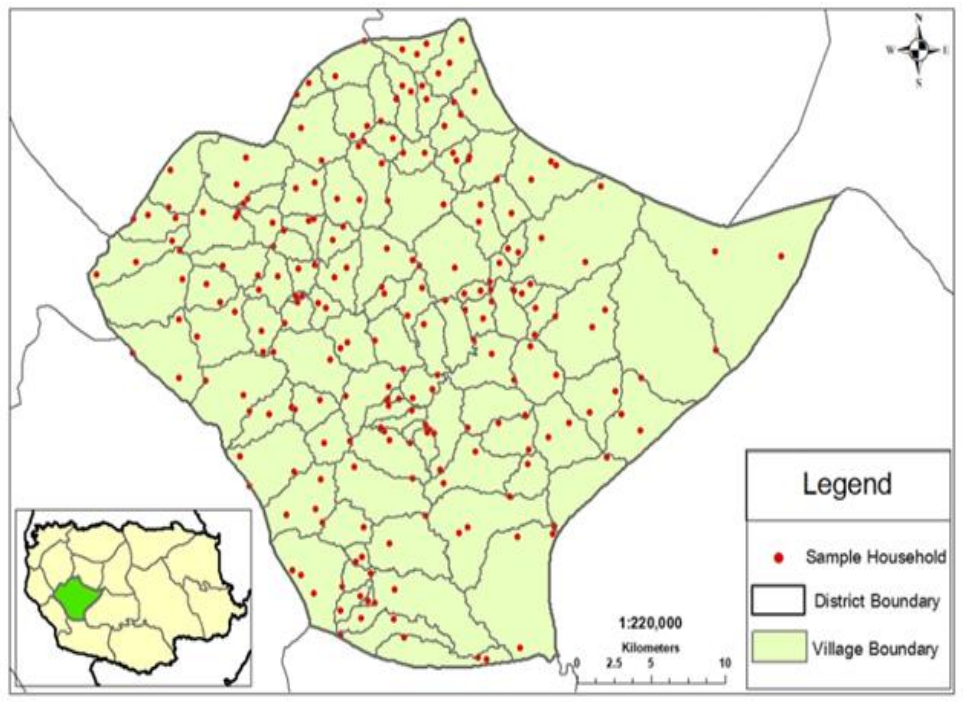

Figure 1. Map of Champhone District in Savannakhet Province.

\subsection{Data Collection}

The data used in the study were collected through face-to-face interviews. For the convenience of interviewing and data collection, we used the census and survey processing system (CSPro) via a mobile phone or tablet computer instead of paper questionnaires.

To determine the appropriate sample size, we used a two-stage sampling technique. This method is useful when the population size is large [12]. In the first stage, the population 
was separated into clusters; in the second stage, the elements of the clusters were randomly selected [13]. In the study, we then listed all the villages according to Lao Agricultural Census [14] in the Champhone District. After selecting the villages where the major crop was rice, we randomly selected households engaged in wet-season lowland rice farming. The sample size was measured using the proportion sample size formula suggested by [15]. The formula for the sample size can be expressed as

$$
n=\frac{Z^{2} p k}{\sigma^{2}}
$$

where $n$ is the sample size, $Z$ represents the standard normal distribution (value to be found in the standard normal table depending on the number of observations), $p$ is the measured proportion of the whole population in the Champhone District, $k$ is 1-p, and $\sigma$ is the margin of error. According to Lao Census of Agriculture [12], rice farming households account for approximately 82 percent of the total population in the Champhone District. Assuming a $p$ of $0.82,95$ percent confidence levels, and a Z-value of 1.96, the sample size was estimated to be 227. The study survey was conducted from 25 May to 30 June 2019; data from 230 farm households were collected [5].

Table 1 presents the summary statistics. The average return for wet-season lowland rice was approximately 4269 Laotian kip ( 1 LAK $=0.22$ dollar, 2019) per household. The average production of paddy rice was $3034 \mathrm{~kg} / \mathrm{ha}$. The minimum production was $300 \mathrm{~kg} / \mathrm{ha}$, and the maximum was $30,000 \mathrm{~kg} / \mathrm{ha}$. The average selling price of wet-season lowland rice was $1919 \mathrm{LAK} / \mathrm{kg}$. The average size of cultivation area was 1.67 ha (range: $0.11-12.01$ ) per household, which implies that most farms are small. The average wage was 13,430 LAK. Most farming households used improved rice varieties to local or traditional varieties. For planting methods, manual transplanting was preferred to other planting methods, such as machine transplanting and muddy broadcasting. Approximately 5 percent of farmers obtained loans from the bank and the village foundation, and 9 percent of farmers received extension services from the government or the farmer association. Of all rice farming household heads, 94 percent were male, and 6\% female. The average age of household heads was about 49.7 years. Most were literate, and had received a primary school level of education.

Table 1. Summary Statistics.

\begin{tabular}{|c|c|c|c|c|c|}
\hline & Unit & Mean & Std. Dev & Min & Max \\
\hline \multicolumn{6}{|c|}{ Inputs } \\
\hline Rate of return & $\%$ & -58.69 & 2.48 & -29.40 & 0.89 \\
\hline Return & LAK & 4269.32 & 4370.32 & 322.00 & $45,600.00$ \\
\hline Total rice production & $\mathrm{Kg}$ & 3034.13 & 3331.83 & 300.00 & $30,000.00$ \\
\hline Selling price & LAK & 1919.37 & 206.48 & 1000.00 & 3500.00 \\
\hline Planted areas & Ha & 1.67 & 1.44 & 0.11 & 12.01 \\
\hline Labor costs & LAK & $13,430.39$ & $19,060.54$ & 0.00 & $80,000.00$ \\
\hline Seed costs & LAK & $354,418.23$ & $23,540.56$ & 0.00 & $400,000.00$ \\
\hline Irrigation costs & LAK & 1069.57 & 5129.28 & 0.00 & $45,000.00$ \\
\hline Organic fertilizer costs & LAK & $142,184.80$ & $246,081.20$ & 0.00 & $2,000,000.00$ \\
\hline Chemical fertilizer costs & LAK & $278,022.20$ & $345,212.10$ & 0.00 & $2,550,000.00$ \\
\hline Maintenance costs & LAK & 3347.83 & $29,723.78$ & 0.00 & $320,000.00$ \\
\hline Other costs & LAK & 34.13 & 38.15 & 0.00 & 117.00 \\
\hline \multicolumn{6}{|c|}{ Factors of efficiency(or inefficiency) } \\
\hline Sex & male $=1$ & 0.94 & 0.24 & 0.00 & 1.00 \\
\hline Age & year & 49.74 & 11.14 & 19.00 & 82.00 \\
\hline Marital status & married $=1$ & 0.94 & 0.26 & 0.00 & 1.00 \\
\hline Education & $\begin{array}{l}\text { at least secondary } \\
\text { school }=1\end{array}$ & 0.91 & 0.27 & 0.00 & 1.00 \\
\hline
\end{tabular}


Table 1. Cont.

\begin{tabular}{|c|c|c|c|c|c|c|}
\hline & & Unit & Mean & Std. Dev & Min & $\operatorname{Max}$ \\
\hline \multicolumn{2}{|c|}{ Planted areas } & $\mathrm{Ha}$ & 1.67 & 1.44 & 0.11 & 12.01 \\
\hline \multicolumn{2}{|c|}{ Access to loan } & yes $=1$ & 0.05 & 0.21 & 0.00 & 1.00 \\
\hline \multicolumn{2}{|c|}{ Extension services } & yes $=1$ & 0.09 & 0.29 & 0.00 & 1.00 \\
\hline \multirow{4}{*}{ Planting method } & Manual transplanting & yes $=1$ & 0.53 & 0.49 & 0.00 & 1.00 \\
\hline & Machine transplanting & yes $=1$ & 0.12 & 0.32 & 0.00 & 1.00 \\
\hline & Muddy broadcasting & yes $=1$ & 0.23 & 0.42 & 0.00 & 1.00 \\
\hline & Other & yes $=1$ & 0.20 & 0.34 & 0.00 & 1.00 \\
\hline \multirow{3}{*}{ Rice varieties } & Thadokkham8 & yes $=1$ & 0.30 & 0.46 & 0.00 & 1.00 \\
\hline & Thadokkham11 & yes $=1$ & 0.17 & 0.37 & 0.00 & 1.00 \\
\hline & Others & yes $=1$ & 0.09 & 0.28 & 0.00 & 1.00 \\
\hline
\end{tabular}

note: 1 LAK $=0.22$ dollar (2019).

\subsection{Conceptual Framework}

There are two different approaches to efficiency measures, parametric Stochastic Frontier Analysis (SFA) and non-parametric Data Envelopment Analysis (DEA). The data envelopment analysis has an advantage in that it requires less structure on the shape of frontier in order to measure efficiency. However, the DEA approach forces any deviation from the frontier line to the inefficiency part and thus it easily exaggerates average inefficiency if there exist any noises [16]. In the SFA approach, the application for a translog production function is convenient and flexible to estimate cost or profit efficiency $[17,18]$. Thus, we adopted a stochastic frontier analysis to evaluate the profit efficiency of wet-season lowland rice farms in Laos.

There are two approaches for measuring profit inefficiency using a stochastic frontier model [4]. One approach is to follow the general process of a production frontier model, and the other is to utilize a profit function based on the duality principle. The latter approach is based on profit function and profit share equations, leading to more efficient estimates into one system $[4,19]$. This approach has the advantage of being able to estimate both technical and allocative efficiency, because the residuals of the share equations reflect allocative inefficiency. However, this approach assumes that the shadow price is affected by market distortions. As the consequences of market distortion in Lao rice markets are not clear, study analyses were based on a typical production frontier model. As the study does not follow the formal procedure for profit function, we need two assumptions-the time period for generating profits, and the types of inputs to reduce violations of the profit maximization theory. The first assumption was to treat profits gained from wet-season lowland rice production from a short-term perspective. Based on the production decision theory, profits would be zero and all inputs become variable inputs in a competitive market from a long-term perspective [20]. Next, we assumed that there are quasi-fixed inputs in the short run. Quasi-fixed inputs are indivisible inputs for which a fixed amount must be employed for any positive output level [21]. In contrast to fixed inputs, quasi-fixed inputs are not necessarily purchased when the output becomes zero. Based on these assumptions, a production frontier model is used to evaluate profit efficiency.

In a production frontier model, profits are replaced with the rate of revenue. According to [4], the rate of revenue can be used to analyze profit gains or losses. The rate of revenue is expressed as a percentage change in the current revenue and initial revenue. To create the rate of revenue, current revenues are calculated based on actual selling prices and observed production of wet-season lowland rice, and desirable revenues are calculated based on official market price and observed production of wet-season lowland rice.

Figure 2 shows the profit system of wet-season lowland rice. Labor and machinery are treated as quasi-fixed inputs in this study. Because of imperfect market conditions, and sociopolitical and institutional constraints in Laos rice markets [8], rice prices are divided into official market prices and observed market prices. To find the overall factors affecting profit inefficiency, we included socioeconomic variables such as sex, age, education, and marital status. 


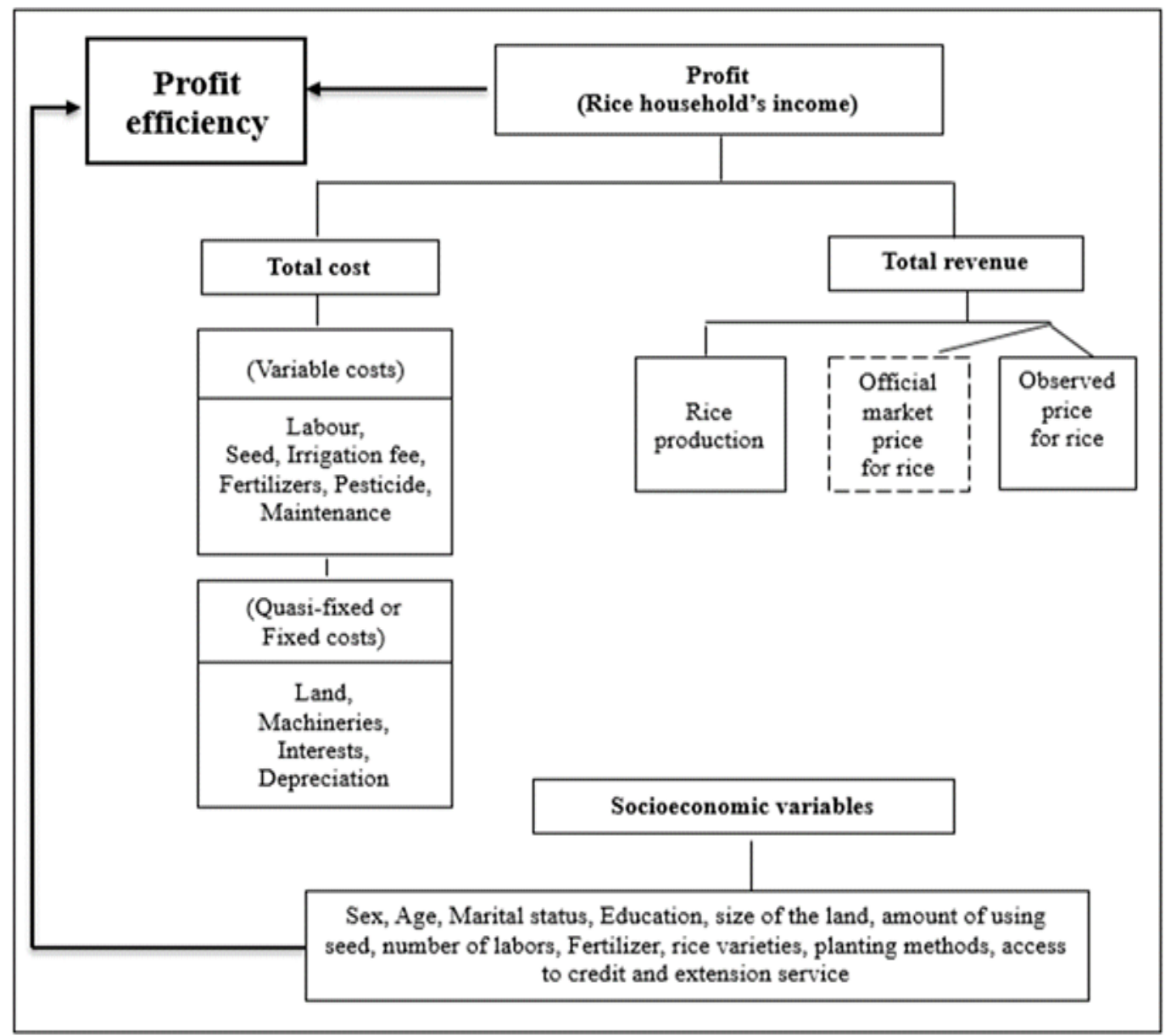

Figure 2. Profit System of Wet-Season Lowland Rice.

Profit Frontier Model

The technical efficiency of an estimation can be modeled as either output-oriented or input-oriented. If the farmer achieves a higher output under the given inputs, it can be designed using an output-oriented model. In contrast, when a farmer can manage to use fewer inputs with the observed output, an input-oriented model is more appropriate [4]. Based on the output-oriented model, we assumed that the objective of the farmer is to gain higher profits under the given inputs and outputs. A stochastic frontier model to measure profit efficiency can be expressed as

$$
\begin{gathered}
\ln R o R_{i}=\ln R_{o} R_{i}^{*}-u_{i}, u_{i} \geq 0, \\
\ln R_{0} R_{i}^{*}=f\left(X_{i} ; \beta\right)+v_{i},
\end{gathered}
$$

where $R o R_{i}$ represents the rate of return at the $i$ th farm, $R o R_{i}^{*}$ represents a frontier level for the rate of return at the $i$ th farm, $X_{i}$ is a vector for variables related to wet-season lowland rice production, which consists of total rice production, rice selling price, labor cost, seed cost, irrigation fee, organic fertilizer cost, chemical fertilizer, maintenance cost, and other operating expenses at the $i$ th farm; $\beta$ is a vector of coefficients; $u_{i}$ is an error term that explains production inefficiency; and $v_{i}$ is a random error with zero mean. Equations (2) and (3) can be combined to give:

$$
\ln R o R_{i}=f\left(X_{i} ; \beta\right)+v_{i}-u_{i} .
$$


Inefficiency model of wet-season lowland rice farms can be expressed as:

$$
u_{i}=\delta_{0}+\sum_{i=1}^{I} \delta_{i} Z_{i}+w_{i}
$$

where $u_{i}$ is the inefficiency, $Z_{i}$ is the vector of exogenous variables such as sex, age, marital, education, cultivation area, access to credit, extension services, planting method and rice types that affect efficiency, $\delta^{\prime}$ s are coefficients, and $w_{i}$ is the error term.

Based on the above models, the estimation procedure in the study is followed by a two-stage approach [22]. In the first stage, efficiency scores of rice farms are estimated by a stochastic frontier function. In the second stage, the estimated efficiencies are regressed against the exogenous variables affecting profit efficiencies or inefficiencies, using the ordinary least squares (OLS). Based on the results from the stochastic frontier model, we calculated the frequency of profit efficiency level of each rice farm.

\section{Results}

The results of the profit frontier model analysis are given in Table 2. First, we examined the variance parameters. The value of gamma $(\gamma)$, the variance ratio of the profit frontier model (significant at the 5 percent level) is 0.6130 . This implies that approximately 61 percent of the variation in the data collected is produced from an inefficiency error term, while approximately 29 percent of the variation is produced from pure noise [22]. The estimated value $\left(\sigma^{2}\right)$ of the total variance is 0.3370 and it indicates the difference between actual data and frontier output.

Table 2. Estimates from Stochastic Profit Frontier Model of Wet-Season Lowland Rice.

\begin{tabular}{|c|c|c|c|}
\hline Variables & Coefficients & Std. Dev & $t$-Statistics \\
\hline \multicolumn{4}{|l|}{ Dependent variable (Rate of return) } \\
\hline Constant & $0.712 * *$ & 0.315 & -2.260 \\
\hline Total rice production $(\mathrm{kg})$ & $2.348^{* * *}$ & 0.035 & 67.086 \\
\hline Selling price per kg (kip) & $2.151^{* * *}$ & 0.099 & 21.727 \\
\hline Labor costs (kip) & $-1.139 * * *$ & 0.048 & -23.729 \\
\hline Seed costs (kip) & $-0.137^{* * *}$ & 0.001 & -137.000 \\
\hline Irrigation fee (kip) & $-0.010^{* * *}$ & 0.001 & -10.000 \\
\hline Organic/manure fertilizer costs (kip) & $-0.002 * *$ & 0.001 & -2.000 \\
\hline Chemical fertilizer costs (kip) & $-0.006^{* * *}$ & 0.001 & -6.000 \\
\hline Maintenance and repair costs (kip) & $-0.004^{* * *}$ & 0.001 & -4.000 \\
\hline Other costs (kip) & -0.011 & 0.024 & -0.458 \\
\hline \multicolumn{4}{|l|}{ Variance Parameters } \\
\hline $\begin{array}{l}\text { Gamma } \\
\gamma=\sigma_{U}^{2} /\left(\sigma_{U}^{2}+\sigma_{V}^{2}\right)\end{array}$ & $0.613^{* * *}$ & 0.068 & 9.054 \\
\hline $\begin{array}{l}\text { Sigma Squared } \\
\sigma^{2}=\sigma_{U}^{2}+\sigma_{V}^{2}\end{array}$ & $0.337^{* * *}$ & 0.072 & 4.700 \\
\hline
\end{tabular}

In the stochastic profit frontier model (Table 2), the coefficients indicate the percentage change in the rate of revenue of a rice farm household with respect to a percentage change in output, selling price, and costs of variable inputs or quasi-fixed inputs. Except for other costs, we found that labor, seed, irrigation, fertilizers, and maintenance costs are statistically significant at one and five percent levels, respectively. Total rice production and selling price have positive signs with respect to the rate of revenue; however, labor, seed, irrigation, fertilizers, and maintenance costs have negative signs with respect to the 
rate of revenue. This indicates that if rice farm households produce more than before or sell at a higher price, then it positively affects profitability. On the other hand, high input costs negatively affect profitability.

The results from the inefficiency model presented in Table 3. The sign of the parameter estimate has the opposite meaning. We found that rice farms run by male heads are statistically significant at the 10 percent level and have a negative sign. This means that if a farm increases the number of male workers, the rate of revenue of the farm increases by 11.24 percent. The farmer's age is statistically significant at the 10 percent level and shows a positive sign. This indicates that as farmers grow older, the rate of revenue from rice farming decreases. The marital status and education level of a household head positively affect the rate of revenue. The rice cultivation area shows negative signs and is statistically significant at the 1 percent level. We conclude that rice farm households who rent or have a large cultivation area are more likely to have higher yields, which improves profitability. The authors of $[23,24]$ showed that higher production leads to higher profits. Access to credit and extension services has a negative sign, and these are statistically significant at the 5 percent level. This implies that farm households who can access credit and participate in extension services have more chances to increase revenue. With regard to planting methods, only machine transplanting was statistically significant at the 5 percent level. This indicates that machine transplanting positively affects revenue. As regards seed varieties, the improved varieties of Thadokkham8 and Thadokkham 11 were not statistically significant. Other varieties, including local varieties, were negative and statistically significant at the 10 percent level. Several studies have suggested that the use of improved rice varieties had mixed results on agricultural productivity. The author of [25] reported that in Sudan, local rice varieties positively affected rice production, but some improved rice varieties did not.

Table 3. Inefficiency Model of Wet-Season Lowland Rice.

\begin{tabular}{|c|c|c|c|c|}
\hline \multicolumn{2}{|c|}{ Variables } & Coefficients & Std. Dev & $t$-Statistics \\
\hline \multicolumn{5}{|l|}{ Inefficiency Model } \\
\hline \multicolumn{2}{|c|}{ Constant } & -8.286 & 19.066 & -0.435 \\
\hline \multicolumn{2}{|c|}{ Sex $($ male $=1)$} & $-11.240 *$ & 7.245 & -1.551 \\
\hline \multicolumn{2}{|c|}{ Age } & $9.725^{*}$ & 8.399 & 1.158 \\
\hline \multicolumn{2}{|c|}{ Marital Status (married = 1) } & -0.278 * & 0.221 & -1.258 \\
\hline \multicolumn{2}{|c|}{ Education (primary school = 1) } & $-10.932 *$ & 9.502 & -1.150 \\
\hline \multicolumn{2}{|c|}{ Rice cultivation area } & $-40.587^{* * *}$ & 9.708 & -4.181 \\
\hline \multicolumn{2}{|c|}{ Access to credit (yes = 1) } & $-148.890 * *$ & 71.893 & -2.071 \\
\hline \multicolumn{2}{|c|}{ Extension services $($ yes $=1$ ) } & $-27.973 *$ & 21.414 & -1.306 \\
\hline \multirow{4}{*}{ Planting methods } & Manual transplanting & 2.595 & 7.481 & 0.347 \\
\hline & Machine transplanting & $-132.009^{* *}$ & 51.368 & -2.570 \\
\hline & Muddy broadcasting & 1.890 & 8.591 & 0.220 \\
\hline & Others & $15.118 *$ & 9.061 & 1.668 \\
\hline \multirow{3}{*}{ Rice varieties } & Thadokkham8 & 0.116 & 6.524 & 0.018 \\
\hline & Thadokkham11 & 5.883 & 7.015 & 0.839 \\
\hline & Other & $-7.347^{*}$ & 6.453 & -1.139 \\
\hline
\end{tabular}

Note: ${ }^{* * *}$ and ${ }^{* *}$ indicate significance at $1 \%$ and $5 \%$, respectively.

Table 4 presents the frequencies of profit efficiencies of rice farms. Based on the results of profit efficiencies of rice farms, each rice famer is categorized by a profit efficiency range. The profit efficiency range is from 0 to 100 in increments of 10 percent. Around 57 percent of farmers produced rice at a profit efficiency level of more than 80 percent. However, about 
20 percent of farmers continued to produce wet-season lowland rice at a profit efficiency level of less than 10 percent. The average level of profit efficiency was 68.45 percent, which suggests that with the current circumstances, farmers in Champhone District at Savannakhet Province could potentially increase their profitability by 31.55 percent.

Table 4. Distribution of profit efficiency.

\begin{tabular}{|c|c|c|}
\hline Profit Efficiency Level (\%) & Frequency & Percentage \\
\hline $0-10$ & 45 & 19.57 \\
\hline $10-20$ & 2 & 0.87 \\
\hline $20-30$ & 1 & 0.43 \\
\hline $30-40$ & 1 & 0.43 \\
\hline $40-50$ & 4 & 1.74 \\
\hline $50-60$ & 4 & 1.74 \\
\hline $60-70$ & 10 & 4.35 \\
\hline $70-80$ & 23 & 10.00 \\
\hline $80-90$ & 55 & 23.91 \\
\hline $90-100$ & 85 & 36.96 \\
\hline Total & 230 & 100.00 \\
\hline Minimum & \multicolumn{2}{|c|}{0.02} \\
\hline Maximum & \multicolumn{2}{|c|}{99.99} \\
\hline Mean & \multicolumn{2}{|c|}{68.45} \\
\hline Standard Deviation & \multicolumn{2}{|c|}{36.27} \\
\hline
\end{tabular}

\section{Discussion}

This study attempts to estimate the profit efficiency of wet-season lowland rice farms from a short-term perspective in Laos using a stochastic production frontier model. The results show that rice farm households produce more than before or sell at a higher price, which positively affected short-term profitability. On the other hand, high input costs, such as labor, seed, irrigation, fertilizers, and maintenance costs, negatively affected short-term profitability. Except for production and selling prices, labor costs substantially affected profitability. Labor costs varied widely, with the highest cost being 80,000 Kip (Table 1) during transplanting and harvesting seasons. From a short-term perspective, the government should stabilize labor costs during busy seasons, and from a long-term perspective, should improve machinery and equipment to reduce labor costs. We found that rice farm households who rent or have a large cultivation area are more likely to have higher yields. Expanding cultivation area must be carefully considered. The government needs to advise farmers regarding the appropriate farm size [5]. In our inefficiency model analysis, the education level of farm household head, accessibility to credit, and participation of extension services significantly affected short-term profitability. The role of education in the present study showed the different results from the studies of $[8,9]$. They found that the education level did not play an important role in improving productivity, however, we showed that the education level played a significant role in increasing profit.

Based on the results, we recommend that the Laos government needs to organize training programs not only on the use of improved rice varieties and chemical fertilizers to achieve higher rice production, but also on negotiation skills to deal with price and to create product value. In addition, the government needs to pay more attention to extension services for small-scale farms, which leads to low rice production. If farmers are able to use the new farming techniques and have access to better knowledge and information about farming, they can increase production, and obtain high profits. Finally, the government must concentrate on education in order to increase the profits of farmers. Education will 
play a key role in learning economic concepts such as capitalism, principles of marketing, trade, and so on.

There are some suggestions for further studies. In order to empirically improve a disadvantage of a parametric stochastic frontier analysis, a distribution-free approach can be applied and compared. The corrected ordinary least square estimator proposed by [26] could be dealt with by heteroscedasticity. Besides a suggestion for an empirical model, we can suggest comparing the profit efficiency of rice farms across Asian countries to analyze different factors for improving profit efficiency. Comparing relevant studies on efficiency measurement of technological changes in Chinese agriculture could be a good example for Laos' policy initiative to improve rice production. One study evaluated the changes in efficiency after the Chinese government adopted hybrid rice to improve rice self-sufficiency, using a stochastic production and cost frontier model [27]. They found significant difference in technical and allocative efficiency between conventional and hybrid rice. Another study examined the technical and allocative efficiency of technological changes in Chinese agriculture during the reform period (1980-1993), using the frontier shadow cost function [28]. The author found different results during the first stage of reform and the second stage of reform since each stage had different agricultural policies.

Author Contributions: Conceptualization, S.K. and Y.L.; methodology, Y.L.; software, S.K.; validation, Y.L., J.B.C.; formal analysis, S.K.; investigation, S.K.; resources, S.K.; data curation, S.K.; writing-original draft preparation, S.K.; writing-review and editing, Y.L. and J.B.C.; visualization, S.K. and Y.L.; supervision, Y.L. All authors have read and agreed to the published version of the manuscript.

Funding: This research received no external funding.

Institutional Review Board Statement: Not applicable.

Informed Consent Statement: Not applicable.

Conflicts of Interest: The authors declare no conflict of interest.

\section{References}

1. Ali, F.; Parikh, A.; Shah, K.M. Measurement of Profit Efficiency Using Behavioral and Stochastic Frontier Approaches. Appl. Econ. 1994, 26, 181-188. [CrossRef]

2. Bravo-Ureta, B.E.; Pinheiro, A.E. Efficiency Analysis of Developing Country Agriculture: A Review of the Frontier Function Literature. Agric. Resour. Econ. Rev. 1993, 22, 88-101. [CrossRef]

3. Aigner, D.; Lovell, C.; Schmidt, P. Formulation and estimation of stochastic frontier production function models. J. Econ. 1977, 6, 21-37. [CrossRef]

4. Kumbhakar, C.S.; Wang, H.-J.; Horncastle, P.A. A Practitioner's Guide to Stochastic, Frontier Analysis Using Stata; Cambridge University Press: New York, NY, USA, 2015.

5. Khouthikoumane, S. An Analysis of Profitability of Rice Production on Wet Season Lowland Rice in Champhone District at Savannakhet Province, Lao PDR. Master's Thesis, Kangwon National University, Chuncheon, Korea, 2019.

6. Joseph, L.S.; Damian, M.G.; Gilead, I.M. Profit loss per hectare according to profit efficiency level among smallholder rice farmers in Central Liberia. Afr. J. Agric. Res. 2016, 11, 3012-3019. [CrossRef]

7. International Rice Research Institute. Lao People's Democratic Republic Rice Policy Study; International Rice Research Institute: Los Baños, Philippines, 2012.

8. Sayavong, V. Productivity and Technical Inefficiency of Paddy Rice Production in Laos: A Case Study of Farm Household Survey. In East Asian Development Network; Eadn Working Paper No. 118; National Economic Research Institute: Vientiane, Laos, 2017.

9. Sayavong, V. Technical Inefficiency in Paddy Rice Production in Laos. Asean Econ. Bull. 2018, 35, 257-274. [CrossRef]

10. Inthavong, H.K. Factors Influencing Rice Production Efficiency in Ban Home, Laos. Master's Thesis, McGill University, Montreal, QC, Canada, 2005.

11. Agricultural Statistics Yearbook 2018; Center for Agricultural Statistics, Ministry of Agriculture and Forestry: Vientiane, Laos, 2018.

12. Berg, S. Double Sampling for Cluster- or Two-Stage Sampling. Int. Stat. Rev. 1972, 40, 13. [CrossRef]

13. Cadima, E.L. Sampling Methods Applied to Fisheries Science: A Manual; Food and Agriculture Organization of the United Nations: Rome, Italy, 2005.

14. Lao Agricultural Census 2011; Center for Agricultural Statistics, Ministry of Agriculture and Forestry: Vientiane, Laos, 2011.

15. Cochran, W.G. Sampling Techniques, 2nd ed.; John Wiley and Sons, Inc.: New York, NY, USA, 1963. 
16. Huang, T.-H.; Wnag, M.-H. Comparison of Eonomic Efficiency Estimation Methods: Parametric and Non-Parametric Techniques. Manch. Sch. 2002, 70, 682-709. [CrossRef]

17. Theodoridis, A.M.; Psychoudakis, A. Efficiency Measurement in Greek Dairy Farms: Stochastic Frontier vs. Data Envelopment Analysis. Int. J. Econ. Sci. Appl. Res. 2008, 1, 53-67.

18. Theodoridis, A.M.; Anwar, M. A comparison of DEA and SFA methods: A case study of farm households in Bangladesh. J. Dev. Areas 2011, 45, 95-110. [CrossRef]

19. Wang, J.; Wailes, E.J.; Cramer, G.L. A Shadow-Price Frontier Measurement of Profit Efficiency in Chinese Agriculture. Am. J. Agric. Econ. 1996, 78, 146-156. [CrossRef]

20. Johnston, J. An Econometric Study of the Production Decision. Q. J. Econ. 1961, 75, 234-261. [CrossRef]

21. Thoma, C.; Maurice, S.C. Managerial Economics, 13th ed.; McGraw-Hill Education: New York, NY, USA, 2016.

22. Hayatullah, A. Crop Diversification and Technical Efficiency in Afghanistan: Stochastic Frontier Analysis; CREDIT Research Paper No. 17/04; The University of Nottingham: Nottingham, UK, 2017.

23. Binuyo, G.; Abdulrahman, S.; Yusuf, O.; Timothy, A.J. Technical Efficiency of Rain-fed Lowland Rice Production in Niger State, Nigeria. Asian J. Agric. Ext. Econ. Sociol. 2016, 9, 1-12. [CrossRef]

24. Parikh, A.; Ali, F.; Shah, M.K. Measurement of Economic Efficiency in Pakistani Agriculture. Am. J. Agric. Econ. 1995, 77, 675-685. [CrossRef]

25. Maruod, E.M. Impact of Improved Seeds on Small Farmers Productivity, Income, and Livelihood in Umruwaba Locality of North Kordofan, Sudan. Int. J. Agric. For. 2013, 3, 203-208.

26. Winsten, C. Discussion on Mr. Farrell's Paper. J. R. Stat. Soc. 1957, 120, 282-284.

27. Xu, S.; Jeffrey, R.S. Efficiency and Technical Progress in Traditional and Modern Agriculture: Evidence from Rice Production in China. Agric. Econ. 1998, 28, 157-165. [CrossRef]

28. Fan, S. Technological Change, Technical and Allocative Efficiency in Chinese Agriculture: The Case of Rice Production in Jiangsu. J. Int. Dev. 2000, 12, 1-12. [CrossRef] 